American Journal of Pharmaceutical Education 2017; 81 (6) Article 110.

\title{
RESEARCH
}

\section{Improving Pharmacy Student Communication Outcomes Using Standardized Patients}

\author{
Chris Gillette, PhD, ${ }^{\mathrm{a}}$ Michael Rudolph, MS, ${ }^{\mathrm{b}}$ Nicole Rockich-Winston, PharmD, MS, \\ Robert Stanton, PharmD, MBA, ${ }^{\mathrm{b}}$ H. Glenn Anderson Jr., PharmD ${ }^{\mathrm{b}}$ \\ ${ }^{a}$ Wingate University School of Pharmacy, Wingate, North Carolina \\ ${ }^{\mathrm{b}}$ Marshall University School of Pharmacy, Huntington, West Virginia \\ Submitted June 3, 2016; accepted August 25, 2016; published August 2017.
}

Objective. To examine whether standardized patient encounters led to an improvement in a student pharmacist-patient communication assessment compared to traditional active-learning activities within a classroom setting.

Methods. A quasi-experimental study was conducted with second-year pharmacy students in a drug information and communication skills course. Student patient communication skills were assessed using high-stakes communication assessment.

Results. Two hundred and twenty students' data were included. Students were significantly more likely to have higher scores on the communication assessment when they had higher undergraduate GPAs, were female, and taught using standardized patients. Similarly, students were significantly more likely to pass the assessment on the first attempt when they were female and when they were taught using standardized patients.

Conclusion. Incorporating standardized patients within a communication course resulted in improved scores as well as first-time pass rates on a communication assessment than when using different methods of active learning.

Keywords: active learning, flipped classroom, standardized patients, communication

\section{INTRODUCTION}

The flipped classroom is a method of instruction that is intended to be student- or learner-centered rather than instructor-centered. In the flipped classroom, the traditional course structure is inverted: the knowledge dissemination that once occurred during class time is instead transmitted to the student through recorded lectures, articles, and other materials outside of the classroom. ${ }^{1-4}$ This in turn allows the instructor to dedicate class time to active learning activities focused upon student mastery and application of the material. Theory suggests that student learning can be enhanced through active learning in the flipped classroom because it encourages self-reflection, higher-order thinking, and can motivate students to develop the desired knowledge and skills. ${ }^{2}$ Furthermore, the flipped classroom can accommodate the uniqueness of

Corresponding Author: Chris Gillette, Wingate University School of Pharmacy, 515 N. Main St. Wingate, NC 28174. Tel: 704-233-8799. Fax: 704-233-8332. E-mail: c.gillette@ wingate.edu

Note: At the time of the study, Dr. Gillette was affiliated with Marshall University School of Pharmacy each student's learning style because he or she can be allowed to work at his or her own pace, and the instructor can identify areas where each student is having difficulty and provide individualized assistance. ${ }^{3,4}$

A range of activities have been identified in the literature as being considered active learning, including problem-based learning, team-based learning, simulation, games, group discussions, and interactive case studies. ${ }^{5}$ Among these, one of the earliest to appear in higher education is the use of standardized patient encounters, which has served as an instructional tool in pharmacy programs since at least the 1970 s. $^{6}$ Standardized patients (SP) are individuals who are trained to portray a patient or family member of a patient, in a consistent manner. ${ }^{7,8}$ SPs are useful because they allow health care students to practice different skills, such as physical examinations, patient counseling, and education. Employing SPs in the classroom is beneficial because students can safely make mistakes without causing harm to a real patient. Both medical and pharmacy students have been shown to view simulation with SPs favorably. ${ }^{9,10}$ Medical students have rated SP encounters as being more applicable in future interactions with patients than peer role-play. ${ }^{10}$ Presumably, students may view the 


\section{American Journal of Pharmaceutical Education 2017; 81 (6) Article 110.}

simulated environment as more "lifelike" and are inclined to take it more seriously than peer role-play (RP).

Even though SP has been shown to be effective in teaching students in the health professions different skills, such as patient counseling, history taking, and physical assessment, this teaching method also requires significant time and monetary resources from institutions that wish to incorporate SP activities into their teaching. Frequently, some institutions employ staff whose sole responsibility is simulation to ensure that faculty have access to a robust pool of actors/actresses. Building cases and training SPs to portray a specific role requires significant time from faculty. Further, SPs are usually recruited from the community and are paid either a salary or an hourly stipend. Therefore, it is no surprise that there has been recent research examining whether other teaching methods that do not require additional salaried/hourly employees, such as RP, are as effective or more effective than SP activities. ${ }^{10-14}$

Findings to date about the effectiveness of SP vs RP have been mixed, with some studies showing that SP is superior to RP, some showing that RP is as effective as SP activities, and some showing that RP is more effective than SP activities. ${ }^{10-16}$ One study also examined the cost-effectiveness of SP activities compared to RP and found that RP was cheaper and more effective than SP. ${ }^{13}$ However, previous studies have generalizability issues, such as using a two-day workshop that compared SP vs $\mathrm{RP}$, only examined one aspect of communication (end-oflife care), compared one class of students to another class of students, or had small sample sizes $(\mathrm{N}<40) .{ }^{10-14}$

To build on previous research, this study used a quasi-experimental design to investigate the performance of PharmD students across three administrations of a second-year drug information and communication course. The objective of this study was to examine if teaching patient communication skills to students using SP would result in improved scores and first-time pass rates on a high-stakes communication assessment as compared to peer RP/patient cases. The null hypothesis of this study was that there would be no difference in first attempt pass rates and total scores for students who were taught using RP compared to SP.

\section{METHODS}

This study was approved by the Marshall University Institutional Review Board. The study used a quasiexperimental design to compare the effectiveness of two active learning methods in the flipped classroom model for teaching patient communication to professional pharmacy students: RP vs SP. It was conducted over three administrations of a required second-year course, PHAR622: Drug Information and Communication Skills. All of the following concepts are taught within this course: acquisition and utilization of medical and drug information resources, introductory biostatistics, and pharmacist-patient communication. Table 1 presents the course objectives. The theme of the course is centered on assisting students in their understanding of how to obtain and interpret medical and drug information and then communicate that information to other health care professionals and patients who have no health care background. PHAR622 is a 2-credit hour course meeting once a week for 2 hours and 15 minutes over a 15 -week semester.

The first two administrations $(2013,2014)$ utilized case studies, discussion, and RP. The third administration followed the same course structure and content, but included a series of five SP encounters in place of case studies, discussion, and RP. Students in all three years were assessed using the same communication assessment. A description of the different course formats, communication assessment, and data analysis is provided in the subsequent paragraphs.

In the first two offerings of PHAR622 in 2013 and 2014, a flipped classroom technique was used, where course content was delivered prior to scheduled class sessions and each class session was dedicated to applying that content through active learning. During class, the first 15-20 minutes included a brief lecture and time for student questions. Students then completed an active learning activity designed to enhance their understanding of the application of the concepts. The following communication topics were examined during the course: theories applicable to pharmacist-patient communication (health

Table 1. PHAR622-Drug Information and Communication Skills Course Objectives

\section{Objective}

Discuss different types of pharmacist-patient relationships

Demonstrate effective patient counseling skills

Evaluate and select appropriate communication theories to apply to different patient counseling scenarios

Demonstrate the ability to use professional drug information references and articles to answer a drug information request

Develop a drug information module in the format recommended by the American Society of Health-systems Pharmacists (ASHP) Evaluate study design, methods, and results of research studies 


\section{American Journal of Pharmaceutical Education 2017; 81 (6) Article 110.}

belief model, shared decision-making, motivational interviewing, social cognitive theory, fuzzy trace model, and Andersen's Behavioral Model of Health Services Use; pharmacist-patient discussion of risks/benefits associated with medications; communicating with patients who have low health literacy/cultural competency; Internet use and pharmacist-patient communication; and enabling patient self-management.

An example of a typical class session was the students watched a lecture about health literacy and how patient outcomes are affected by health literacy (or lack thereof) prior to the class meeting. When students arrived to class, the first 15-20 minutes included a brief lecture and time for student questions about the concept(s). Next, students formed pairs and completed the Rapid Estimate of Adult Literacy in Medicine-Short Form (REALMSF) and Test of Functional Health Literacy in Adults [TOFHLA (teaching version)], which took about 5 minutes. ${ }^{17,18}$ Afterward, there was another brief discussion around the advantages and disadvantages of each method of measuring health literacy. Subsequently, students were presented with a case that included a patient who had low health literacy and experienced poor health outcomes. Students were asked to discuss the case in their group (groups of eight), and the remainder of class time was spent discussing how the student could apply communication interventions to enhance that patient's understanding of their medications. The final few minutes of class time were set aside for any additional student questions. Finally, one week prior to the assessment, all students were required to complete a practice SP encounter. Students were asked to use the rubric to self-assess their performance prior to the actual assessment. However, this was not required.

The 2015 course offering followed nearly an identical course structure and format as the two previous offerings. The same content, instructor, and recorded lectures were used. Further, all active learning events were the same except for the five new SP encounters that were used in place of five case studies or RP activities from 2013 and 2014. On the days when SP were used, the class, which had 76 students, was divided into two groups, one had 40 students and the other 36 . The first group met during the regular 2-hour class period, and the second during an additional 2-hour period on the same day. Consistent with other activities in the course, the class session began with a brief 15- to 20-minute lecture and time for students to ask questions about content. Immediately thereafter, students rotated in groups of eight to meet one-on-one with SP for about 15 minutes each. Patient cases focused upon the topic of the day, such as risk communication, health literacy, etc. Prior to speaking with the patient, students researched the case and corresponding medications using online tertiary drug information resources or primary references. Students counseled the patients following the same rubric that would later be used to assess the students during the communication assessment. After all students had rotated through and completed the SP counseling and other active learning exercises, there was a brief instructor-led discussion during the final 15-20 minutes of class. The instructor used this time to provide feedback to all students based on a discussion of how to incorporate that topic into patient counseling sessions and what students could do to improve their communication with actual patients.

Students' SP encounters were recorded, and the instructor graded those encounters on two occasions during the semester to provide formative feedback using the rubric that the students would be graded on during the assessment. Students also were encouraged to watch and assess the recordings of their peers as well as themselves using the rubric. However, peer assessment was not recorded as a grade for the course and was not required. This provided additional opportunities for feedback and student self-reflection. A dichotomous variable (simulation) was created within the dataset to identify students who participated in the 2015 course ( $1=$ yes, $0=$ no).

The final examination for the course in all three years was a high-stakes communication assessment. Students who did not pass the communication assessment during the didactic curriculum were not allowed to progress to Advanced Pharmacy Practice Experiences. The case presented to the students, the rubric, and the grader of the rubric (the instructor of the course), were the same in each instance. The grading rubric has a possible total of 30 points and is based on the Indian Health Services method of medication counseling and assessing patient self-efficacy for correct medication use based upon social cognitive theory (Table 2). ${ }^{19,20}$ Students across all three cohorts received the Objective Structured Clinical Exam (OSCE) rubric at the beginning of the semester and also were encouraged to practice with their peers throughout the semester. A modified Angoff method was used by a team of faculty to establish minimum competency score. ${ }^{21}$ The team consisted of clinical faculty and the course instructor as judges. The judges were provided the case and the rubric. Individual rubric items were evaluated using a four-step process: judges were asked to imagine a group of 100 minimally competent second-year pharmacy students; for each item, each judge estimated the number of these students who would provide that information to the SP; if there was a difference greater 


\section{American Journal of Pharmaceutical Education 2017; 81 (6) Article 110.}

Table 2. Counseling Assessment Rubric

For Each of the Following, Indicate Whether the Student Performed the Described

Performed

Activity by Checking the Box to the Right

$(\mathrm{Yes}=1, \mathrm{No}=\mathbf{0})$

Greets patient (introduces self, identifies as pharmacist, asks patient's name)

Obtains complete record of current health conditions

Obtains complete record of medications (nonprescription, prescription, vitamins, herbals)

Tells patient that there was a problem with a medication, that pharmacist has talked to physician

and discusses the change in medication

Asks 'What did the doctor tell you the medication was for?'

Stated the medication's trade name

Stated the medication's generic name

Stated the purpose of the medication

Identified the expected benefits (cure, reduce symptoms, slow/prevent disease)

Verified patient's understanding of expected benefits of medication

Asks 'How did the doctor tell you to take the medication?'

Identified the medication dosage that the patient will be taking

Identified the route of administration (oral, subcutaneous, intravenous, nasal, etc.)

Identified frequency to take the medication (QID, Q4H, etc.)

Assesses patient's self-efficacy in using device correctly (technique)

Asks patient to demonstrate/talk through steps of using device (prop provided)

Provided directions for use/administration

Verified patient's understanding of how to use the medication

Asks 'What did the doctor tell you to expect?'

Identified adverse effects associated with the prescribed medication and what to do if an adverse effect occurs

Discussed actions that may prevent or minimize adverse effect occurrence

Suggested actions to take and who to notify when adverse effects occur

Verified patient's understanding of adverse effects

Asks 'What questions do you have for me?' or something similar

Expresses interest in and concern for the patient

Uses appropriate communication level for the patient

Pace, tone, volume appropriate enough to communicate clearly

Language and gestures were appropriate and polite

Wears appropriate attire

Shows positive attitude toward patient

Points out of 30

$\mathrm{QID}=$ four times daily

$\mathrm{Q} 4 \mathrm{H}=$ every four hours

than $10 \%$ in the probability estimates, then there was a short discussion and re-estimation of the number of minimally competent students who would provide that information to the SP; and final probability estimates were averaged.

Through this approach, a cut-score of 23 out of 30 (76.67\%) was determined to be the minimum passing score on the assessment. A variable was created in the dataset to identify students who received at least a 23 on their first OSCE attempt $(1=$ yes, $0=$ no). Students who did not successfully pass the OSCE were required to undergo remediation activities provided by the instructor and retake the assessment using a different case. The remediation process consisted of a brief lecture and allowed each student to ask questions to improve their performance.
In addition to students' scores on the communication assessment, we included possible explanatory variables in our dataset to account for student background characteristics and prior achievement. Students' undergraduate and pre-requisite grade point averages (GPAs), Pharmacy College Admission Test (PCAT) composite scores, age, and gender were compiled from the Pharmacy College Application Service system. ${ }^{22}$ We also used students' P1 scores on the Pharmacy Curriculum Outcomes Assessment (PCOA). The PCOA is a comprehensive standardized national exam and available for all pharmacy students within the United States. The PCOA tests four major content areas, basic biomedical sciences, pharmaceutical sciences, social/behavioral/administrative sciences, and clinical sciences. ${ }^{23}$ At our institution, 


\section{American Journal of Pharmaceutical Education 2017; 81 (6) Article 110.}

all students from the first through the third professional years take the PCOA annually to allow the school's administration to document student scores and change in scores throughout their didactic training. We incorporated in our dataset students' total scaled score, total percent correct, and percent correct on each of the drug information and literature evaluation skills sub-content areas. Both the literature evaluation and drug information subsections are components of the clinical sciences section.

All analyses were conducted using SAS 9.3 (Cary, NC). First, descriptive statistics are presented using means and proportions. Second, we compared entering characteristics between the two groups of students (simulation vs. no simulation used) to examine if there were any systematic differences in prior achievement that may have confounded the relationship between the independent variable, simulation, on student achievement in the course. These comparisons were made using independent samples $t$-tests and chi-square tests where appropriate. Next, independent samples $t$-tests were used to examine the relationship between the independent variable and the outcome of interest, total score on the assessment. A Pearson chi-square test examined if there was a significant relationship between being taught with simulation and the proportion of students who passed on the first attempt. Additionally, we created a new dichotomous variable, assessment fail, by reverse coding the pass variable and calculated an odds ratio (OR) to determine the risk of failing the communication assessment when taught with SP.

Finally, multivariable linear and logistic regression were used to examine the association between whether students were taught using simulation and their communication scores as well as the likelihood of passing the communication assessment on the first attempt, while controlling for various background characteristics. The model presented for each regression is the model of best fit for the dependent variable. Results are reported in both unstandardized beta coefficients $(\beta)$ for the linear regression and OR in the logistic regression. An alpha level of .05 was used to assess statistical significance.

\section{RESULTS}

Baseline characteristics of the students in the simulation and the traditional flipped classroom groups are presented in Table 3. The groups were similar in all characteristics before matriculation as well as their $\mathrm{P} 1$ performance on the PCOA in terms of total scaled score, total percent correct, literature evaluation percent correct, and drug information percent correct.

The mean communication score for the two cohorts that were taught using RP was 22.7 and 23.6 respectively $p=.08$ ). Students who engaged in simulation activities during PHAR622 had significantly higher scores, on average, than students in either of the first two cohorts (26.47 vs $23.12, p<.001)$.

It was also found that a significantly higher percentage of students who were taught using SP passed the first attempt when compared to those who were taught using RP $(90.79 \%$ vs $61.1 \%, p<.0001)$. The OR of failing the first attempt was $0.16(95 \% \mathrm{CI}=0.07-0.37, p<.0001)$ when simulation was used instead of traditional classroombased active learning in the flipped classroom. Thus, the probability of failing the first attempt without simulation was approximately $39 \%$, and the probability of failing the first attempt with simulation was approximately $10 \%$.

Table 4 presents the multivariable linear regression results examining the association between use of simulation and communication scores while controlling for student background and prior achievement variables. Table 5

Table 3. Matriculating Students' Characteristics and PCOA Examination Score $(\mathrm{N}=220)$

\begin{tabular}{|c|c|c|c|c|}
\hline Independent Variable & $\begin{array}{c}\text { Traditional Classroom } \\
\text { Group }(n=144) \text { Mean (SD) }\end{array}$ & $\begin{array}{c}\text { Simulated Patient } \\
\text { Group }(n=76) \text { Mean }(\text { SD) }\end{array}$ & $t$ value & $p$ value \\
\hline Undergraduate GPA* & $3.08(0.45)$ & $3.13(0.46)$ & -.83 & .41 \\
\hline PCAT Composite Score* & $42.83(22.14)$ & $46.75(23.88)$ & 1.21 & .23 \\
\hline P1 PCOA Total Scaled Score* & $265.22(43.39)$ & $257.3(54.19)$ & -1.18 & .24 \\
\hline P1 PCOA Total Percent Correct* & $46.47(8.18)$ & $46.38(10.14)$ & -.07 & .94 \\
\hline $\begin{array}{l}\text { P1 PCOA Drug Information } \\
\text { Percent Correct* }\end{array}$ & $55(17.9)$ & $54(23.8)$ & -.10 & .92 \\
\hline Student Mean Age & $24.31(5.56)$ & $23.07(4.04)$ & -1.72 & .09 \\
\hline Gender-Female $^{\mathrm{a}} \%$ (n) & $59(85)$ & $49(37)$ & $2.15^{\mathrm{a}}$ & .14 \\
\hline
\end{tabular}

*Mean (SD), ${ }^{\text {a }}$ Chi-square; PCOA = Pharmacy Curriculum Outcomes Assessment, PCAT=Pharmacy College Admissions Test 


\section{American Journal of Pharmaceutical Education 2017; 81 (6) Article 110.}

Table 4. Multivariable Linear Regression Predicting Communication Assessment Scores $(\mathrm{N}=220)$

\begin{tabular}{lccc}
\hline Variable & Unstandardized $\boldsymbol{\beta}$ & $\mathbf{9 5 \%}$ CI & $\boldsymbol{p}$ value \\
\hline PCOA P1 Total Scaled Score & 0.001 & $-0.01-0.01$ & 0.81 \\
Undergraduate GPA & 1.35 & $0.48-2.23$ & 0.003 \\
Gender-Female & 1.44 & $0.67-2.20$ & 0.0003 \\
PCAT Composite Score & 0.02 & $-0.01-0.04$ & 0.14 \\
Simulation-Yes & 3.45 & $2.64-4.25$ & $<0.0001$ \\
Age & -0.004 & $-0.08-0.07$ & 0.91 \\
\hline
\end{tabular}

$\mathrm{R}^{2}=0.33$, Adjusted $\mathrm{R}^{2}=0.31 ; \mathrm{CI}=$ Confidence Interval; PCOA $=$ Pharmacy Curriculum Outcomes Assessment

shows the results from the logistic regression model for whether students passed the assessment the first attempt. From Table 4, students were significantly more likely to have higher scores on the communication assessment if they were: female (unstandardized $\beta=1.44, p=.0003$ ), taught with simulation (unstandardized $\beta=3.45, p<.001$ ), and had higher undergraduate GPAs (unstandardized $\beta=1.35, p=.003)$. For the main independent variable, simulation, estimates indicate that use of SP is associated with a 3.45 point increase $(11.3 \%)$ in student scores on the assessment, holding other factors in the model constant. Student age was not significantly associated with higher communication assessment scores. From Table 5 , students were significantly more likely to pass the first attempt if they were female $(\mathrm{OR}=2.31,95 \%$ $\mathrm{CI}=1.20-4.43)$, and in the simulation group $(\mathrm{OR}=6.94$, $95 \%, \mathrm{CI}=2.88-16.72, p<.001)$. Students' undergraduate GPA, PCAT composite score, and age were not significantly associated with the likelihood of passing the communication assessment on the first attempt.

\section{DISCUSSION}

This study examined the effect of SP encounters on students' first-time communication assessment scores and pass rates. Controlling for other factors, we estimate that

Table 5. Multivariable Logistic Regression Predicting Likelihood of Passing the Communication Assessment the First Time $(\mathrm{N}=220)$

\begin{tabular}{lccc}
\hline Variable & OR & $\mathbf{9 5 \%}$ CI & $\boldsymbol{p}$ value \\
\hline PCOA P1 Total Scaled & 1.001 & $0.99-1.01$ & .78 \\
$\quad$ Score & & & \\
Undergraduate GPA & 1.60 & $0.76-3.39$ & .22 \\
Gender-Female & 2.31 & $1.20-4.43$ & .01 \\
PCAT Composite Score & 1.01 & $0.99-1.03$ & .32 \\
Standardized Patient & 6.94 & $2.88-16.72$ & $<.0001$ \\
$\quad$ Group-Yes & & & \\
Age & 1.00 & $0.94-1.07$ & .91 \\
\hline
\end{tabular}

Multivariable $\mathrm{OR}=$ Odds Ratio, $\mathrm{PCOA}=$ Pharmacy Curriculum Outcomes Assessment, PCAT=Pharmacy College Admissions Test; $\mathrm{CI}=$ Confidence Interval students scored approximately 3 points higher (11\%) on the assessment when they were taught with SP to simulation, as compared to active learning using case studies, $\mathrm{RP}$, and/or other active learning events that did not expose students to SP. We also found that a significantly higher percentage of students passed the communication assessment the first attempt when SP were used during the course. Therefore, we conclude that use of SP in teaching communication may be superior to RP in terms of improving student patient counseling ability.

Prior research that has examined the utility of SP in medical and pharmacy education has provided mixed results when examining SP vs other active learning modalities. On the one hand, some studies have shown that when students were taught using SP they had higher scores on exams that addressed patient counseling. ${ }^{24,25}$ On the other hand, several studies have shown that RP is at least equivalent, if not superior, to SP counseling in terms of student outcome achievement. ${ }^{10-14}$ Additionally, one study has shown that RP is also more cost-effective than using SP. ${ }^{13}$ Future research should examine the cost-effectiveness of using SP vs traditional classroom-based activities in pharmacy education, such as peer RP and case discussions.

The results from this study provide new insight as to whether SP can be used effectively to teach communication skills to health professions students, such as student pharmacists. Our study shows a clear association between using SP and improved communication skills. We attribute some of the differences between our findings and previous research on the effectiveness of SP use to study design. For example, some studies were conducted over exceedingly short time periods (eg, two days) or examined limited aspects of health professional-patient communication. Our study followed students over multiple weeks and included multiple opportunities for feedback from instructors and peers and student self-reflection. Further, our study also suggests that not all active learning methods are equivalent, and that one active learning event may lead to better student outcomes, even when everything else (ie, instructor, content, and quality of students) is comparable. 


\section{American Journal of Pharmaceutical Education 2017; 81 (6) Article 110.}

One of the strengths of this study is the quasiexperimental design. We used a variation of the interrupted time series design, where we obtained measurements on the outcome of interest prior to instituting a new policy of course instruction and measured the outcome of interest afterward. The only differences among the three course administrations were the replacement of several case study/RP activities with SP encounters and formal critiques from the instructor in the most recent year. Further, the students in the control and treatment groups were statistically similar prior to matriculation and during their time in the doctor of pharmacy program prior to enrolling in the study course. This reduces the possibility of a confounder related to student background characteristics in our findings.

This study also found that female students were more likely to pass the assessment the first attempt and achieved higher scores, on average, than male students. Previous research has found that differences exist in how male and female physicians communicate with their patients, with females having longer visits and engaging in more psychosocial conversation. ${ }^{26}$ However, most of the research that has been done on the effect of gender on communication style and patient-centeredness has been conducted in physician-patient communication. Future research should investigate whether there are also gender differences in pharmacist-patient communication.

We also found that students with higher undergraduate GPAs and PCAT composite scores were more likely to have higher scores. This is consistent with previous research in pharmacy education, which suggests previous GPA and PCAT scores are important predictors of student success in pharmacy school. ${ }^{27,28}$ This study provides further evidence of how previous student knowledge and behavior is important in shaping a student's future success as a professional pharmacy student.

An interesting finding of this study is that the PCOA was not associated with a higher score on the communication assessment. This could have occurred because the PCOA may test different aspects of communication than our rubric. Another explanation is that knowledge about communication may not be indicative of a student's ability to counsel appropriately. Future research needs to examine whether higher PCOA scores are indicative of a student's future ability to practice.

However, there are some limitations to our findings. Even though substantial efforts were made to ensure a high degree of comparability among the three administrations of the course, we acknowledge the possibility that some variance in student performance may be attributed to improvement in the professor's teaching ability due to increasing familiarity with the content. However, we believe the effect of this professor-related "growth" is relatively small because the same pre-recorded lectures were used. Moreover, the professor only talked to the students for 10-15 minutes in each session to summarize the content and answer questions. Another possible limitation is that students may have shared information with the latter cohort(s) because the case and rubric used for the communication assessment were the same across all three years. We have attempted to limit this effect in that all patient-student encounters were one-on-one, and the only individual with access to the recordings was the course instructor. Further, even if students did share information about the medication and/or the case, these aspects were ancillary and not the primary focus of the assessment. The primary focus was to evaluate whether students had learned how to correctly ask open-ended questions and apply the Indian Health Services counseling model and social cognitive theory in a high-stakes communication assessment. At most, students in previous cohorts may give advice to students in latter cohorts to ensure they do not miss the open-ended questions, which was already communicated by the instructor during the low-stakes instructor feedback. Our analysis also is limited to only one course administration that utilized SPs. Future research should include multiple years of SP to examine the trends. Finally, we did not collect any data specifically about the students' perceptions of SP encounters. Future research should examine pharmacy students' perceptions about SP encounters to teach communication skills.

\section{CONCLUSION}

Our study found that utilizing SP instead of case study/RP activities to teach patient communication skills to student pharmacists resulted in improved student counseling scores as well as first-time pass rates on a communication assessment. This suggests that when teaching communication, use of SP to aid in application may result in improved student counseling ability compared to other active learning methods such as peer RP. We believe these findings have implications for other health sciences disciplines (ie, medicine, nursing, physician assistant, etc.).

\section{REFERENCES}

1. Bergmann J, Sams A. Flip Your Classroom: Reach Every Student in Every Class Every Day. Arlington, VA: International Society for Technology in Education; 2012.

2. Prince M. Does active learning work? A review of the research.

$J$ Eng Educ. 2004;93(3):223-231.

3. Herreid CF, Schiller NA. Case study: case studies and the flipped classroom. J Coll Sci Teach. 2013;42(5):62-67.

4. Fulton K. Upside down and inside out: flip your classroom to improve student learning. Learn Lead Tech. 2012;39(8):12-17. 


\section{American Journal of Pharmaceutical Education 2017; 81 (6) Article 110.}

5. Waltz CF, Jenkins LS, Han N. The use and effectiveness of active learning methods in nursing and health professions education: a literature review. Nurs Educ Persp. 2014;35(6):392-400.

6. Love DW, Wiese HJ, Henson RE, Parker CL. Teaching interviewing skills to pharmacy residents. Am J Hosp Pharm. 1978;35(9):1073-1074.

7. What is a standardized patient? Drexel University College of Medicine website. http://www.drexel.edu/medicine/Academics/ MD-Program/Innovative-Medical-Technology/StandardizedPatients-Program/What-Is-a-Standardized-Patient/. Accessed April 18, 2016.

8. Standardized patient frequently asked questions. University of Pittsburgh School of Medicine Office of Medical Education website. http://www.omed.pitt.edu/standardized/faq.php. Published January 13, 2012. Accessed April 18, 2016.

9. Robinson JD, Bray BS, Willson MN, Weeks DL. Using human patient simulation to prepare student pharmacists to manage medical emergencies in an ambulatory setting. Am J Pharm Educ. 2011;75(1): Article 3.

10. Bosse HM, Nickel M, Huwendiek S, Junger J, Schultz JH, Nikendei C. Peer role-play and standardized patients in communication training: A comparative study on the student perspective on acceptability, realism, and perceived effect. BMC Med Educ. 2010;10:27.

11. Lane C, Hood K, Rollnick S. Teaching motivational interviewing: using role play is as effective as using simulated patients. Med Educ. 2008;42(6):634-644.

12. Mounsey AL, Bovbjerg V, White L, Gazewood J. Do students develop better motivational interviewing skills through roleplay with standardized patients or with student colleagues? Med Educ. 2006;40(8):775-780.

13. Bosse JM, Nickel M, Huwendiek S, Schultz JH, Nikendei C. Cost-effectiveness of peer role play and standardized patients in undergraduate communication training. BMC Med Educ. 2015; 15:183.

14. Curtis JR, Back AL, Ford DW, et al. Effect of communication skills training for residents and nurse practitioners on quality of communication with patients with serious illness: a randomized trial. JAMA. 2013;310(21):2271-2281.

15. Austin Z, Gregory P, Tabak D. Simulated patients vs. standardized patients in objective structured clinical examinations. Am J Pharm Educ. 2006;70(5):Article 119.
16. Rickles NM, Tieu P, Myers L, Galal S, Chung V. The impact of a standardized patient program on student learning of communication skills. Am J Pharm Educ. 2009;73(1):Article 4.

17. Arozullah AM, Yarnold PR, Bennett CL, et al. Development and validation of a short-form, rapid estimate of adult literacy in medicine. Med Care. 2007;45(11):1026-1033.

18. Parker RM, Baker DW, Williams MV, Nurss JR. The test of functional health literacy in adults: a new instrument for measuring patients' literacy skills. J Gen Intern Med. 1995;10(10):537-541. 19. Boyce RW, Lam N, Muravez SN. Evaluating Indian health service counseling model in the community pharmacy setting. Res Soc Admin Pharm. 2014;10(5):e22.

20. Baranowski T, Perry CL, Parcel GS. How individuals, environments, and health behavior interact: social cognitive theory. In: Glanz K, Rimer BK, Viswanath K (eds). $4^{\text {th }}$ ed. Health Behavior and Health Education. Hoboken, NJ: John Wiley and Sons; 2008:169-188.

21. Anderson HG Jr., Nelson AA. Reliability and credibility of progress test criteria developed by alumni, faculty, and mixed alumni-faculty judge panels. Am J Pharm Educ. 2011;75(10): Article 200.

22. Pharmacy College Application Service (PharmCAS). PharmCAS website. http://www.pharmcas.org. Accessed January 14, 2016.

23. National Association of Boards of Pharmacy. PCOA Frequently asked questions. https://nabp.pharmacy/programs/pcoa/faqs/.

Accessed May 20, 2015.

24. Lupu AM, Stewart AL, O'Neil C. Comparison of active-learning strategies for motivational interviewing skills, knowledge, and confidence in first-year pharmacy students. Am J Pharm Educ. 2012;76(2):Article 28.

25. Schlegel C, Woermann U, Shaha M, Rethans JJ, van der Vleuten C. Effects of communication training on real practice performance: a role-play module versus a standardized patient module. $J$ Nurs Educ. 2012;51(1):16-22.

26. Roter DL, Hall JA, Aoki Y. Physician gender effects in medical communication: a meta-analytic review. JAMA. 2002;288(6):756-764.

27. Meagher DG, Lin A, Stellato CP. A predictive validity study of the pharmacy college admission test. Am J Pharm Educ. 2006;70(3): Article 53.

28. McCall KL, MacLaughlin EJ, Fike DS, Ruiz B. Preadmission predictors of PharmD graduates' performance on the NAPLEX. Am J Pharm Educ. 2007;71(1):Article 5. 